\title{
A Retrospective Analysis of Intracranial Meningiomas in a Tertiary Health Care Facility in North Central Nigeria
}

\author{
Philip Ojile Akpa ${ }^{1,2, *}$, Barka Vandi Kwaghe ${ }^{1}$, Emmanuel Innocent ${ }^{1}$, Benjamin Samuel Otene ${ }^{1}$, \\ Dominic Akolo Azagaku ${ }^{1}$, Ijeoma Okwudire-Ejeh ${ }^{3}$ \\ ${ }^{1}$ Department of Histopathology, Jos University Teaching Hospital, Jos, Nigeria \\ ${ }^{2}$ Department of Histopathology, University of Jos, Jos, Nigeria \\ ${ }^{3}$ Anatomic Pathology and Forensic Pathology Department, Asokoro District Hospital, Federal Capital Territory, Abuja, Nigeria
}

Email address:

akpaphilip@yahoo.com (P. O. Akpa),philipakpa@gmail.com (P. O. Akpa)

${ }^{*}$ Corresponding author

\section{To cite this article:}

Philip Ojile Akpa, Barka Vandi Kwaghe, Emmanuel Innocent, Benjamin Samuel Otene, Dominic Akolo Azagaku, Ijeoma Okwudire-Ejeh. A Retrospective Analysis of Intracranial Meningiomas in a Tertiary Health Care Facility in North Central Nigeria. American Journal of Laboratory Medicine. Vol. 6, No. 3, 2021, pp. 37-41. doi: 10.11648/j.ajlm.20210603.12

Received: May 16, 2021; Accepted: May 31, 2021; Published: June 7, 2021

\begin{abstract}
Introduction/Aim: There is scanty detailed published literature on meningiomas in Nigeria and other parts of Africa. This study is aimed at exploring the demographics, histopathology and presenting symptoms/signs of meningioma in our tertiary health facility and comparing it with other published literature. Methodology: This is a hospital based retrospective study of all histopathologically diagnosed meningioma cases at the department of histopathology of the Jos University Teaching Hospital in plateau state North-Central Nigeria. The period of review is between the 1 st of January 2012 to the 31 st of December 2020. Materials utilized for this research consisted of Archival histopathology glass slides, paraffin wax tissue blocks, electronic surgical pathology result data base, electronic cancer registry entries and hard copies of patient case files. The age, sex, intracranial location, histomorphological variant, grade and presenting symptom/sign was documented for all cases and analyzed. Results: Thirty-four (34) cases of meningioma out of 87 primary intracranial neoplasms were histopathologically diagnosed over the 9 years of review. There was a female predominance, with a M:F of 1:1.61. The peak age of diagnoses occurred in the $5^{\text {th }}$ and $6^{\text {th }}$ decades for females and males respectively. The commonest histomorphological variant was the Meningothelial type with the commonest intracranial site of diagnosis being the convexities. The most frequently occurring presenting symptom/sign were headache, seizures and visual impairment. Conclusion: Meningioma is the commonest intracranial tumour diagnosed at the Jos University teaching Hospital, In North central Nigeria. This tumour occurs at a relatively younger age in our environment. The sex distribution, variants, grades and symptoms/signs of this tumour in our study conforms to what is obtainable in other parts of the world.
\end{abstract}

Keywords: Intracranial Meningioma, Histomorphological Variants, Nigeria, Meningothelial, Convexity

\section{Introduction}

Meningiomas are in most cases benign tumours arising from arachnoid cap type meningothelial cells of the arachnoid membrane. [1-4]. They are the most common primary intracranial tumour diagnosed worldwide, their reported frequency varies from study to study and generally ranges from between $13-36 \%$ of intracranial neoplasms. [1, 4-10] Certain genetic and environmental risk factors have been associated with the development of meningiomas.
Neurofibromatosis type II and multiple endocrine neoplasia type I have been genetically linked to the development of meningiomas, while ionizing radiation, exogenous female sex hormone use, viral infections, and trauma are proposed environmental risk factors. [1, 3-6, 10-14]

Meningiomas have been reported to occur in varied locations with most cases arising within the intracranial and intraspinal cavity. Sites of meningioma occurrence outside the neural axis include the lungs, skin and adrenal gland. [4, 12] The latest world health organization (WHO) 
classification identifies 15 histomorphological variants of meningioma stratified into Benign (grade I), Atypical (grade II) and Anaplastic (grade III) meningiomas. [2, 5, 7] A majority of meningiomas are WHO grade I tumours and the most commonly diagnosed histomorphological variants of meningioma are the meningothelial, transitional and fibrous types. [4, 5, 7] Meningiomas occur more frequently in females and the incidence increases with age in both males and females. [1, 5, 8, 11] The clinical signs and symptoms of meningioma are usually as a result of compression of adjacent structures and are quite often non-specific. [4] This study aims to analyze the demographics, histomorphological variants, grade and symptoms/signs of meningioma in our environment and to compare our findings with published data from within and outside Nigeria.

\section{Methodology}

This is a retrospective analysis of all cases of intracranial meningioma diagnosed at the Jos university Teaching Hospital (JUTH) department of Histopathology between the 1st January 2012 to 31 st December 2020. JUTH is a tertiary health Institution and a referral center located in Plateau state, in the North-central region of Nigeria. Materials utilized for this research consisted of Archival histopathology glass slides, paraffin wax tissue blocks (in cases of missing or poor quality glass slides), electronic surgical pathology result data base, electronic cancer registry entries and hard copies of patient case files. The patient age at diagnosis, sex, site of tumour within the cranial cavity and symptoms/signs were retrieved and documented using the electronic and hard copy materials containing the relevant information. The histology glass slides of all cases of meningioma diagnosed during the period of review were examined by the authors of this research to determine the histomorphological variant and grade. All cases of primary intracranial neoplasm diagnosed during the period of this review were also reviewed to enable the calculation of the percentage for meningioma from the total. The data obtained was analyzed using Epi info 7 (version 3.5.4) and presented in tables.

\section{Results}

There were thirty-four (34) cases of meningioma out of a total of 87 primary intracranial neoplasms diagnosed histologically during the period of review. Meningiomas had a female predominance with a male to female ratio of $1: 1.61$ $(\mathrm{M}: \mathrm{F}=1: 1.61)$ (table 1$)$. The peak age range for meningioma diagnosis was in the $5^{\text {th }}$ and $6^{\text {th }}$ decades for females and males respectively (table 1). An increased frequency of diagnosis occurred in the $4^{\text {th }}, 5^{\text {th }}$ and $6^{\text {th }}$ decades when both sexes are considered together. The mean age of meningioma diagnosis was $44.7 \pm 15.8$ (47.8 \pm 17.7 for males and $42.8 \pm 14.6$ for females). The meningothelial $(50 \%)$, fibrous $(20.6 \%)$ and transitional $(8.8 \%)$ histomorphological patterns of growth were the most common variants of meningioma diagnosed (table 2). Thirty (30) of the 34 cases of meningioma were grade I tumours and two (2) apiece were grade II and III (table 3). The commonest sites of localization of meningioma within the intracranial cavity were the convexities $(44.1 \%)$ and parasagittal area $(26.5 \%)$ for both males and females (table 4). Headache, seizures and visual impairment featured in $50 \%, 44.1 \%$ and $38 \%$ of patients respectively (table 5).

Table 1. Table showing age and gender distribution of Meningioma cases.

\begin{tabular}{lllll}
\hline S/N & Age range & Males & Females & Total Frequency (\%) \\
\hline 1 & $0-10$ & 1 & - & $1(2.9)$ \\
2 & $11-20$ & - & 2 & $2(5.9)$ \\
3 & $21-30$ & - & 2 & $2(5.9)$ \\
4 & $31-40$ & 4 & 5 & $9(26.5)$ \\
5 & $41-50$ & 1 & 6 & $7(20.6)$ \\
6 & $51-60$ & 6 & 3 & $9(26.5)$ \\
7 & $61-70$ & - & 3 & $3(8.8)$ \\
8 & $>70$ & 1 & - & $1(2.9)$ \\
& & 13 & 21 & $34(100)$ \\
\hline
\end{tabular}

Table 2. Table showing histomorphological subtypes (variants) of Meningioma.

\begin{tabular}{lllll}
\hline S/N & Total & Males & Females & Total Frequency (\%) \\
\hline 1 & Meningothelial & 7 & 10 & $17(50.0)$ \\
2 & Fibrous & 2 & 5 & $7(20.6)$ \\
3 & Transitional & 2 & 1 & $3(8.8)$ \\
4 & Psammomatous & 1 & - & $1(2.9)$ \\
5 & Microcystic & - & 2 & $2(5.9)$ \\
6 & Papillary & & 2 & $2(5.9)$ \\
7 & Atypical & 1 & 1 & $2(5.9)$ \\
Total & & 13 & 21 & $34(100)$ \\
\hline
\end{tabular}

Table 3. Table showing distribution of meningioma according to WHO grade.

\begin{tabular}{lllll}
\hline S/N & WHO grade & Males & females & Total Frequency (\%) \\
\hline 1 & 1 & 12 & 18 & $30(88.2)$ \\
2 & 2 & 1 & 1 & $2(5.9)$ \\
3 & 3 & - & 2 & $2(5.9)$ \\
& & 13 & 21 & $34(100)$ \\
\hline
\end{tabular}

Table 4. Table showing intracranial localization of meningioma cases.

\begin{tabular}{|c|c|c|c|c|}
\hline $\mathbf{S} / \mathbf{N}$ & Intracranial site & Males & Females & Total Frequency (\%) \\
\hline 1 & $\begin{array}{l}\text { Convexity } \\
\text { Fronto-parietal--4 } \\
\text { Fronto-temporal--3 } \\
\text { Frontal--3 } \\
\text { Temporal--2 } \\
\text { Parietal--1 } \\
\text { Parieto-temporal--1 } \\
\text { Parieto-occipital--1 }\end{array}$ & 6 & 9 & $15(44.1)$ \\
\hline 2 & Parasagittal & 4 & 5 & $9(26.5)$ \\
\hline 3 & Parafalcine & - & 2 & $2(5.9)$ \\
\hline 4 & Sphenoid wing & 1 & 2 & $3(8.8)$ \\
\hline 5 & Olfactory groove & 1 & 1 & $2(5.9)$ \\
\hline 6 & Petroclival & 1 & & $1(2.9)$ \\
\hline 7 & Posterior cranial fossa & - & 1 & $1(2.9)$ \\
\hline 8 & Tuberculum sella & - & 1 & $1(2.9)$ \\
\hline Total & & 13 & 21 & $34(100)$ \\
\hline
\end{tabular}


Table 5. Table showing frequency of presenting clinical symptoms and signs.

\begin{tabular}{lll}
\hline S/N & Clinical symptom/sign & Frequency (\%) \\
\hline 1 & Headache & $17(50.0)$ \\
2 & Seizures & $15(44.1)$ \\
3 & Visual impairment & $13(38.0)$ \\
4 & Syncope/ loss of consciousness & $4(11.8)$ \\
5 & Hemiparesis & $3(8.8)$ \\
6 & Eye protrusion & $2(5.9)$ \\
7 & Flaccid paralysis & $1(2.9)$ \\
8 & Vomiting & $3(8.8)$ \\
9 & Hearing impairment & $1(2.9)$ \\
10 & Abnormal gait & $1(2.9)$ \\
11 & Behavioral changes & $1(2.9)$ \\
12 & Incontinence (urine and fecal) & $1(2.9)$ \\
13 & Amnesia & $1(2.9)$ \\
14 & Dizziness & $1(2.9)$ \\
15 & Anosmia & $1(2.9)$ \\
\hline
\end{tabular}

\section{Discussion}

Meningiomas are the single most common type of intracranial tumour diagnosed at the Jos university teaching hospital histopathology department, accounting for 39\% of all primary intracranial neoplasms within the period of review. Meningioma was the most common primary intracranial tumour diagnosed in similar studies from tertiary health facilities in Enugu (south-eastern Nigeria), Sokoto (North-western Nigeria) and Lagos (south-western Nigeria). The documented percentages for meningioma are $34.8 \%$, $41.7 \%$ and $48.2 \%$ in Enugu, Sokoto and Lagos respectively. [15-17] A study by Ukpene et al at the Korle Bu Teaching Hospital in Accra, Ghana reported meningiomas as 39.3\% of primary intracranial tumours but were second to gliomas in frequency of occurrence. [18] The documented percentage ranges from between $15-36 \%$ in studies from different parts of the world. [1, 4-10] The high percentage of meningioma amongst intracranial tumours documented in these studies is supported by a documented higher incidence of meningioma in people of the black race. [12] The annual reported incidence rates per 100,000 population in Blacks, whites and Asians is 9.1, 7.4 and 4.8 respectively in the United States of America. [4] Studies have revealed that histologically diagnosed meningiomas are an under-estimation of the true prevalence. Imaging studies have shown a $0.9 \%$ prevalence of asymptomatic meningiomas in the adult population, while autopsy studies suggest a prevalence of about $3 \%$ in individuals over the age of 60 years. [11]

Meningiomas can occur in people of all age groups with the risk increasing with age. The median age of diagnosis worldwide is about 65 years. [1, 4, 6] The peak age range for meningioma diagnosis in our study was in the 5 th and 6 th decades for females and males respectively. There was an increased total frequency of meningioma diagnosis in the $4^{\text {th }}$, $5^{\text {th }}$ and $6^{\text {th }}$ decade, with $73.5 \%$ occurring in patients aged between $30-60$ years and $88.0 \%$ of all cases occurring in patients 60 years and below. This closely correlates with the findings of Mezue et al in Enugu (south-eastern Nigeria) and
Niranjan et al in Bengalore (India) in which $82.0 \%$ and $87.7 \%$ respectively of diagnosed meningioma cases occurred in patients 60 years and below. [1, 19] Fonkem et al in Texas (USA) reported $71.4 \%$ of patients diagnosed above the age of 55 years which contrasts with our findings. [6] The usual increase in incidence of meningioma in elderly patients may be absent in our environment due to the lower life expectancy.

A female predominance of meningioma is widely documented. [1, 2, 4-6] This female predominance of meningioma diagnosis is however not uniform across all age groups and grades of meningioma. [4] Higher grade meningiomas and meningiomas in children tend to have a slight male predominance. $[5,9,11,12]$ The female predominance of meningioma is thought to be less pronounced in the black population. [12] Our study showed a female predominance of meningioma with a male to female ratio (M:F) of 1:1.61. The female predominance of meningioma peaks at about the age of 40-44 years and is very much in keeping with our findings. [5] The male predominance of high grade meningiomas is not reflected in our findings. There is substantial evidence pointing to the role of female sex hormones (especially from exogenous sources) being responsible for the increased risk for meningioma in females. [11, 14] Meningiomas frequently express progesterone receptors and less commonly estrogen receptors, they have also been documented to grow rapidly during pregnancy and in the luteal phase of the menstrual cycle. [20]

The commonest histomorphological variant diagnosed in our study was the meningothelial variant, which accounted for $50 \%$ of all cases followed by the fibrous $(20.6 \%)$ and transitional variants $(8.8 \%)$. Our findings correlate with the pattern seen commonly worldwide but contrasts with the findings of Mezue et al in Enugu, south eastern Nigeria in which the psammomatous variant $(28.2 \%)$ was the most common variant. $[5,4,7,19]$ The heterogeneous histomorphology of meningioma is a reflection of the potential of the arachnoid cells to differentiate along epithelial (e.g secretory and papillary) and mesenchymal (e.g fibrous) lines. [1, 5] The histological appearance even amongst grade I tumours is an important predictor of behavior and hence influences therapy considerations. [2, 5]

A majority $(88.2 \%)$ of the meningiomas in our study were grade I tumours in keeping with the trend worldwide. [3, 4, 9, 11] The grade of a meningioma is important in determining the form of treatment, the patient outcome and risk of recurrence. [1, 7] The WHO grade and completeness of tumour resection are the most important predictors of progression free survival in meningioma patients. [7] Recurrences of grade I meningioma are occasionally of a higher grade and more aggressive than the initial tumour hence complete resection is advised whenever possible. [11]

The commonest site of meningioma diagnosis in the intracranial cavity is the cerebral convexity with tumours occurring in diverse locations including, parasagittal area, parafalcine area, olfactory groove, sphenoid wing, 
tuberculum sella, posterior cranial fossa, and clivus etcetera. $[4,5,9,21]$ Pediatric meningiomas are known to occur in unusual sites such as the within the ventricles. [5] The commonest site of meningioma diagnosis in our study was the cerebral convexities with $44 \%$ of tumours diagnosed at this site

There are no unequivocal symptoms/signs attributable to meningioma, neurological signs and symptoms depend on the location of these tumours, their size and their compressive effects on adjacent structures. [1, 4-6, 22)] Headache and seizures are common but non-specific symptoms commonly observed in meningioma patients. [4] The specific neurological deficits occur as a result of these tumours compressing specific functional parts of the brain. [5] Most of the patients in our study presented with a combination of signs and symptoms. The most common presenting signs/symptoms observed in our study were headache, seizures and visual impairment which featured in 50\%, $44.1 \%$ and $38 \%$ of patients respectively.

Treatment of choice in a majority of patients is surgery owing to the predominance of grade I tumours, however radiotherapy is incorporated in the treatment regimen in higher grade tumours and incompletely resected grade I tumours. $[5,7]$ The prognosis for patients with meningioma is generally favorable, most patients with grade I tumours have an almost normal life expectancy with adequate treatment. $[7,11]$ The overall prognosis is poorer in children and men due to the higher frequency of grade II and III tumours in them. [12]

\section{Conclusion}

This study revealed that meningioma is the single most common intracranial tumour diagnosed in our health facility and similar findings have been reported from within and outside Nigeria. Meningiomas showed a female predominance in our study and the peak age range of diagnosis of meningioma occurred at a relatively younger age compared to established data. The variant distribution, grade and symptoms are consistent with the findings of other authors.

\section{Recommendations}

Additional research, including genetic and molecular investigations is needed to fully elucidate the peculiarities of meningioma in black populations.

\section{Consent}

Not applicable (patients were not identified).

\section{Ethical Approval}

A written ethical approval has been collected and preserved by the authors.

\section{Competing Interests}

The authors declare that they have no competing interests.

\section{Acknowledgements}

We sincerely appreciate all members of staff of the department of Histopathology, cancer registry and patient records unit of the Jos University Teaching Hospital.

\section{References}

[1] Niranjan J, Vishnu PV, Shivarudrappa AS. Histopathological spectrum of meningiomas: A retrospective study. Indian journal of pathology and oncology. 2019; 6 (2): 256-260.

[2] Raza AKMM, Ahmed F, Munni TA, et al. Histomorphological spectrum of meningioma with variants and grading. Adv Surg Res. 2017; 1 (1): 15-17.

[3] Ojo A, Fynn E. Multiple meningiomas. SA Journal of Radiology. 2006; 10 (2): 21-23.

[4] Perry A, Louis DN, Budka A Von Deimling A, Sahm F. Meningioma. In: Hiroko DNL, Otmar O, Webster WK, Cavanee, eds. WHO classification of tumours of the central nervous system. 4th ed. Lyon: IARC press; 2016: 232-245.

[5] Patil PR, Sondankar D. Clinicopathological study of meningioma. Int J Med Res Rev. 2016; 4 (4): 592-601. doi: 10.17511/ijmrr.2016.i04.20.

[6] Fonkem E, Dandashi JA, Stroberg E, Garrett Jr D, Harris FS, El Nihum IM et al. A retrospective analysis of meningioma in central Texas. Journal of epidemiology and global health. 2016; 6: 87-93. http://dx.doi.org/10.1016/j.jegh.2016.01.001

[7] Harter PN, Braun Y, Plate KH. Classification of meningiomas - advances and controversies. Chin Clin Oncol 2017; 6 (Suppl 1): S2. doi: 10.21037/cco.2017.05.02.

[8] Özbayır T, Malak AT, Bektas M, Ilce AO, Celik GO. Information needs of patients with meningioma. Asian Pacific J Cancer Prev. 2011; 12: 439-441.

[9] Fynn E, Khan N, Ojo A. Meningioma - a review of 52 cases. SA Journal of Radiology. 2004; 8 (4): 3-5.

[10] Rogers L, Barani I, Chamberlain M, Kaley TJ, Mcdermott M, Raizer J, Schiff D et al. Meningiomas: knowledge base, treatment outcomes, and uncertainties. A RANO review. J Neurosurg. 2015; 122: 4-23. DOI: 10.3171/2014.7.JNS131644.

[11] Fogh SE, Johnson DR, Barker II FG, Brastianos PK, Clarke JL, Kaufmann TJ et al. Case-based review: Meningioma. Neuro-Oncology Practice. 2016; 3 (2): 120-134. doi: 10.1093/nop/npv063.

[12] Al-Hadidy AM, Maani WS, Mahafza, WS, Al-Najar MS, AlNadii MM. Intracranial meningioma. J Med J. 2007; 41 (1): $37-51$.

[13] Barchana M, Liphshitz I. High Incidence of Benign Brain Meningiomas among Iranian born Jews in Israel may be Linked to both Hereditary and Environmental Factors. Asian Pac J Cancer Prev. 2013; 14 (10): 6049-6053. DOI: http://dx.doi.org/10.7314/APJCP.2013.14.10.6049. 
[14] Wiemels J, Wrensch M, claus EB. Epidemiology and etiology of meningioma. J Neurooncol. 2010; 99: 307-314. DOI 10.1007/s11060-010-0386-3.

[15] Ndubuisi CA, Ohaegbulam SC, Iroegbu LU, Ekuma ME, Mezue WC, Erechukwu UA. Histologically confirmed intracranial tumors managed at Enugu, Nigeria. J Neurosci Rural Pract 2017; 8: 585-590. DOI: 10.4103/jnrp.jnrp_155_17.

[16] Malami SS, Wemimo RM, Kabiru A, Taiwo AA, Umar M, Abiodun AE et al. Histopathological Patterns of Intracranial Tumours at a Tertiary Health Facility in Sokoto, North-West Nigeria. American journal of laboratory medicine. 2019; 4 (6): 119-123. doi: 10.11648/j.ajlm.20190406.17.

[17] Soyemi SS, Faduyile FA, Sanni DA, Mgbehoma AI, Idowu OE, Obafunwa JO. Clinicoepidemiological profile and morphological spectrum of intracranial tumors seen in a tertiary health-care facility: A 6-year retrospective study. Ann Trop Pathol 2020; 11: 166-70.

[18] Ukpene U, Ametefe M, Akoto H, Bankah P, Totimeh T, Wepeba G, Dakura T. Pattern of intracranial tumours in a tertiary hospital in Ghana. Ghana Med J 2018; 52 (2): 79-83. doi: http://dx.doi.org/10.4314/gmj.v52i2.3.

[19] Mezue WC, Ohaegbulam SC, Ndubuisi CC, Chikani MC, Achebe DS. Intracranial meningiomas managed at Memfys hospital for neurosurgery in Enugu, Nigeria. J Neurosci Rural Pract 2012; 3: 320-3.

[20] Perry A, Rosenblum MK. Central Nervous System. In: Goldblum JR, Lamps LW, McKenney JK, Myers JL, eds. Rosai And Ackerman's Surgical Pathology. 11th ed. Philadelphia: Elsevier; 2018: 1948-2085.

[21] Kumar N, Kumar R, Khosla D, Salunke PS, Gupta SK, Radotra BD. Survival and failure patterns in atypical and anaplastic meningiomas: A single-center experience of surgery and postoperative radiotherapy. J Can Res Ther 2015; 11: 7359. DOI: $10.4103 / 0973-1482.151426$.

[22] Westphal M, Lamszus K, Tonn J-C. Meningiomas and meningothelial tumours. In: Tonn J-C, Westphal M, Rutka JT, Grossma SA, eds. Neuro-Oncology of CNS Tumours. Heidelberg: Springer-Verlag; 2006: 81-101. 